\title{
Wnt Signaling and Cadherin Expressions in Different Staging of Colorectal Cancer as Biomarkers for Metastasis: Study of SW480, COLO 320DM, and HCT116 Cellines
}

\author{
Luminturahardjo Winarko $^{1 *(\mathbb{D})}$, Pudji Rahayu ${ }^{2} \mathbb{D}$, Djoko Soeatmadji $^{3}$, Karyono Mintaroem ${ }^{4}$ (D) \\ ${ }^{1}$ Doctoral Program, Faculty of Medicine, Universitas Brawijaya, Malang, Indonesia; ${ }^{2}$ Department of Otorhinolaryngology, \\ Faculty of Medicine, Universitas Brawijaya, Malang, Indonesia; ${ }^{3}$ Department of Internal Medicine, Division of Endocrinology \\ and Metabolism, Faculty of Medicine, Universitas Brawijaya, Malang, Indonesia; ${ }^{4}$ Department of Pathology Anatomy, Faculty \\ of Medicine, Universitas Brawijaya, Malang, Indonesia
}

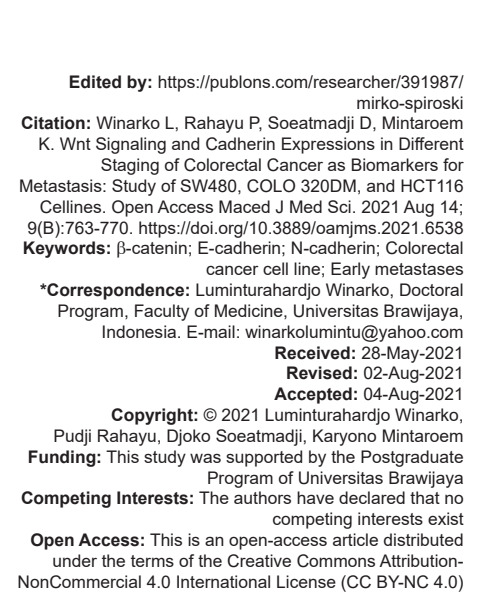

Introduction

Colorectal cancer (CRC), one of the most common types of cancer becomes the top three causes of cancer globally is the fourth cause of death from all types of cancer [1], [2]. In 2013, CRC prevalence in the world was equal to $9 \%$ of all cancer types [3]. To date, the treatment modalities for CRC, which are carried out based on the CRC clinical-stage, and other cancers are surgery, chemotherapy, and radiotherapy [4], [5].

However, the rate of chemotherapy failure due to resistance is still relatively high [6]. Factors causing the occurrence of chemotherapy resistance will result in increased morbidity and mortality rates. Besides, several signaling pathways cause genetic mutations in CRC and intensify chemotherapy resistance incidence [7]. Until recently, two theories widely researched are the gene mutations that occur in two types of CRC, namely, Familial Adenomatous Polyposis and Hereditary Nonpolyposis CRC (HNPCC) [8].

Wnt signaling and cadherin-mediated adhesion processes are involved in embryonal development and cancer progression [3]. Recent studies have revealed crosstalk between Wnt signals and cadherin-mediated cell adhesion [9], [10]. Also, Wnt/ $\beta$-catenin signaling affects chemotherapy resistance incidence [11]. One of the occurring mechanisms is through CBP uptake, a promoter of the multi-drug resistance 1 gene (MDR) proven to be one of the T-cell factor/lymphoid enhancer factor target genes. MDR1 gene is a family of ABC (ATP-binding Cassette) that causes the chemotherapy release mechanism from cells (drug efflux) [12]. Another mechanism, Wnt signaling plays a significant role in the existence of CD34+ tumor cells, known as the phenotype of cancer stem cells and highly resistant to chemotherapy [11]. 
Beta-catenin is a multifunctional protein that has a central role in the homeostasis process in the human body [11]. Wnt/ $\beta$-catenin signaling is a classic pathway involved in modulating the development of cancer cells, i.e., proliferation, resistance, differentiation, motility, adhesion, and apoptosis of cancer cells [13]. However, several signal transducers that affect $\beta$-catenin activity (phosphorylation/degradation) are Glycogen Synthase Kinase $3 \beta$ (GSK-3 $\beta$ ), Axin, and adenomatous polyposis coli [9], [14].

Cadherin will mediate adhesion among cells through the extracellular domain and connect the actin cytoskeleton with catenin through the cytosolic domain [15]. It regulates adhesion among cells, such as morphogenetic modulation and differentiation processes during cell development. Epithelial cells will express E-cadherin, while mesenchymal cells express several cadherin variations, such as $\mathrm{N}$-cadherin, R-cadherin, and cadherin-11. Hence, cadherin is essential in developing cell polarity and cell selection during embryonal development [16], [17].

E-cadherin, a complex localized in the cytoplasm of cancer cells, forms actin cytoskeleton to strengthen adhesion among cells [15]. Since E-cadherin is responsible for maintaining cell polarity, it is considered a marker for cancer cells that have not encountered metastasis [10]. Meanwhile, N-cadherin will experience an upregulation in the mesenchymal cells, which are more motile (mobile) and less polarized than epithelial cells. $\mathrm{N}$-cadherin is expressed in several cell types, such as neuron cells, endothelial cells, stromal cells, and osteoblasts [15], [17].

In the advanced stages of CRC, most will undergo the Epithelial-Mesenchymal Transition (EMT) process resulting in switching between E-cadherin and $\mathrm{N}$-cadherin [15], [18]. Cadherin switching is a decrease in E-cadherin regulation, followed by an increase in $\mathrm{N}$-cadherin regulation when cancer cells undergo EMT [17]. However, E-cadherin expression does not change significantly in some circumstances, but the cells experience an increasing expression of $\mathrm{N}$-cadherin. In some types of cancer, E-cadherin will shift to $\mathrm{N}$-cadherin, but in others, $\mathrm{N}$-cadherin will turn to E-cadherin [10], [15].

This study aimed to analyze the differences in the expression of $\beta$-catenin antibodies in the cytoplasm that are said to increase at the early stages of CRC and the expression of $\beta$-catenin nuclei that increases in the advanced stages. This study also analyzed the differences in the expression of E-cadherin and $\mathrm{N}$-cadherin in CRC cells type SW480, COLO320DM, and HCT116, and to specifically determine the differences in the expression of nuclear and cytoplasmic $\beta$-catenin, E-cadherin, and N-cadherin in SW-480 cell line.

The researchers hypothesized that a higher CRC stage would be followed by an increase in nuclear $\beta$-catenin expression and decreased expressions in the cytoplasm and $\mathrm{N}$-cadherin; while, the $\mathrm{E}$-cadherin expression would continue to decrease. Second, the expressions of nuclear $\beta$-catenin and $\mathrm{N}$-cadherin would increase at Duke B staging (SW480 cell line), which indicates activity of proliferation, migration, and cell metastasis already discovered in the early stage of this cancer.

\section{Materials and Methods}

This study was conducted from July 2020 to September 2020, after obtaining ethical clearance from the Health Research Ethics Commission of Faculty of Medicine, Universitas Brawijaya, Malang, Indonesia, through the decree number 07/EC/KEPK-S3/01/2019. Culture making and immunofluorescence process was conducted at the Parasitology Laboratory and the Biomedical Laboratory, Faculty of Medicine, Universitas Brawijaya.

\section{Samples and specimens}

The samples in this study were models of CRC cell lines Dukes' B, C, and D that were SW480 (ATCC CCL-228), COLO320DM (ATCC CCL-220), and HCT116 (ATCC CCL-247), respectively. The cell lines were ordered from the American Type Culture Collection (ATCC) through Santacruz as the provider. Those three cell lines were grown in growth culture media, i.e., RMPI for SW480, Lebovitz for COLO320DM, and McCoy for HCT116.

\section{Antibodies and reagents}

The primary antibodies used were monoclonal mouse anti-human $\beta$-catenin, E-cadherin, and $\mathrm{N}$-cadherin ordered from Santacruz. This study applied a direct immunofluorescence method since secondary antibodies were not used.

\section{Culturing procedure}

The immunocytochemical procedure was preceded by manufacturing and proliferating the cell culture. Vials containing cell culture were carefully thawed in a water bath at $37^{\circ} \mathrm{C}$. The O-ring was kept and tightly closed, and antibiotics were given to prevent contamination. Thawing was done quickly in about $2 \mathrm{~min}$. Vials were removed as soon as the contents thawed, followed by decontamination by dropping or spraying $70 \%$ ethanol. All actions during this process were aseptic. That vials were transferred to centrifuge tubes containing a complete culture medium (RMPI for SW480 cells, Lebovitz for COLO320DM cells, and 
McCoy for HCT116 cells) and rotated at a speed of $125 \times 9$ for 5-7 min. Cell pellets were then resuspended into complete media and then poured into new culture flasks. Cultures were incubated in an incubator at $37^{\circ} \mathrm{C}$ without $\mathrm{CO}_{2}$. The cells were harvested after reaching 50-70\% cell growth.

\section{Immunofluorescence method}

After the cells grew on the media, fixation was carried out using 4\% paraformaldehyde in paraformaldehyde solution (PBS) (at neutral $\mathrm{pH}$ ) at room temperature for $10 \mathrm{~min}$ and stained directly on multi-well plates, or coverslips. The media were then aspirated, and the coverslips were incubated in $100 \%$ cold methanol. Cell fixation was conducted at $-20^{\circ} \mathrm{C}$ for $15 \mathrm{~min}$, followed by rinsing for 3 times in PBS for 5 min [19], [20].

Immunostaining was done first with by cell permeabilization that was carried out by incubating the coverslips in $0.1 \%$ Triton $\mathrm{X}-100$ in PBS at room temperature for $5 \mathrm{~min}$. The coverslips were then washed to release the permeabilization buffer with PBS for $5 \min [21]$

Specimen block was done in Blocking Buffer for $60 \mathrm{~min}$. The blocking agent used was 1\% BSA in PBST. During the process, the primary antibodies (monoclonal mouse anti-human $\beta$-catenin, E-cadherin, and $\mathrm{N}$-cadherin) were dissolved in Antibody Dilution Buffer. The buffer solution was aspirated, and diluted primary antibody was added to the specimen. After specimens were incubated overnight at $4^{\circ} \mathrm{C}$, rinsing was carried out 3 times in PBS for 5 min [21].

The specimens were incubated in fluorochrome-conjugated secondary antibody diluted in Antibody Dilution Buffer for 1-2 $\mathrm{h}$ at room temperature in the dark and were then rinsed in PBS. The slide cover was incubated using Prolong ${ }^{\circledR}$ Gold Antifade Reagent with 4', 6-diamidino-2-phenylindole (DAPI) to stain the cell nucleus. As counterstaining, fluorescein5-isothiocyanate (FITC) was used to stain the cell cytoplasm. For the best results, the specimens were immediately examined using the correct excitation wavelength. For long-term storage, the slides were stored in a flat position at $4^{\circ} \mathrm{C}$ and protected from light [22], [23]. The sample was added mounting media before covered with a cover glass and then dried on a flat surface. The addition of emersion oil aimed to preserve the sample and increase the refractive index to obtain high-quality images. The sample was ready to be observed under an immunofluorescence microscope for immunofluorescence imaging using ImageJ software [24], [25], [26].

\section{Statistical analyses}

All data on four independent experiments were presented as mean \pm SD. The differences among the three examination groups were analyzed by Statistical Product and Service Solution (SPSS) software, IBM Statistics 20, using the ANOVA method with a significance level of 0.05 and a confidence level of $95 \%$.

\section{Results}

\section{Differences in the intensity of cytoplasmic $\beta$-catenin expression in SW480, COLO320DM, and HCT116 cell lines}

Initially, the analysis on differences in cytoplasmic $\beta$-catenin protein expression was carried out using the digital images through ImageJ software by examining the cytoplasmic density on several cells in several fields of view at $\times 400$. Observations were made by calculating the mean intensity of cytoplasmic $\beta$-catenin expression of approximately 25 cells in the three types of cell lines, SW480, COLO320DM, and HCT116, using the mean fluorescence intensity (MFI) unit. Observations on the intensity of cytoplasmic $\beta$-catenin expression were carried out on the preparations treated with FITC fluorochrome; and, a comparison was made by combining FITC and DAPI (composite) immunofluorescence photos to prove the cytoplasmic expression.

The Kruskal Wallis test was used to find out the differences in the intensity of cytoplasmic $\beta$-catenin expression. The results showed that the mean intensity of cytoplasmic $\beta$-catenin SW480 cell line expression was $25.28 \pm 9.63 \mathrm{MFI}$, COLO320DM cell line was $56.74 \pm 19.02 \mathrm{MFI}$, and HCT116 cell line was $21.65 \pm 0.47 \mathrm{MFI}$. The statistical analysis showed significant differences between the cytoplasmic $\beta$-catenin expression of SW480 and COLO320DM $(25.28 \pm 9.63$ vs. $56.74 \pm 19.02, p<0.05)$, and between the cytoplasmic $\beta$-catenin expression of HCT116 and COLO320DM (21.65 \pm 10.47 vs. 56.74 $\pm 19.02, p<0.05)$. However, none of the intensity of cytoplasmic $\beta$-catenin expression between SW480 and HCT116 cell lines demonstrated significant differences $(25.28 \pm 9.63$ vs. $21.65 \pm 10.47)$.

\section{Differences in the intensity of nuclear $\beta$-catenin expression in SW480, COLO320DM, and HCT116 cell lines}

Figuring out the differences in the intensity of expression of nuclear $\beta$-catenin in SW480, COLO320DM, and HCT116 cell lines were also done using the digital images through ImageJ software. Observations were carried out on 25 cells in several fields of view at 400x magnification. The average area density was calculated based on the MFI unit [Figure 1a]. The One-Way ANOVA test was used to see 


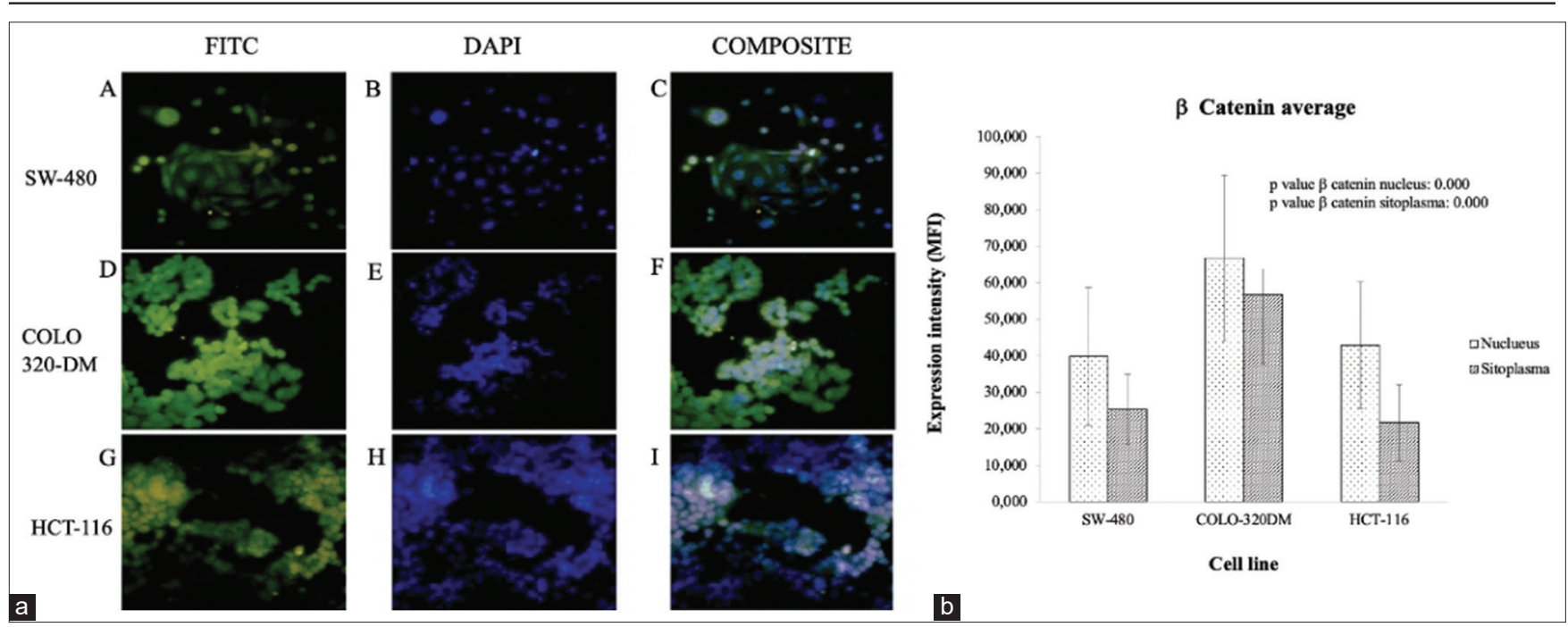

Figure 1: Differences in the intensity of cytoplasmic/nuclear $\beta$-catenin in SW480, COLO320DM and HCT116 cellines. Observasion using immunofluorescence was done to evaluatethe expression of cytoplasmic $\beta$-catenin (FITC), nucleus (DAPI) and composite to distinguish cytoplasmic and nuclear $\beta$-catenin (a). The bar chart shows the mean of differences in the intensity of cytoplasmic and nuclear $\beta$-catenin with significant results $(p<0.05)(b)$

the difference in the intensity of $\beta$-catenin expression in the nucleus, and the resulting expression was $39.80 \pm 18.94 \mathrm{MFI}$ in SW480 cell line, $66.72 \pm 22.69$ MFI in COLO320DM cell line, and $42.85 \pm 17.38$ MFI in HCT116 cell line. Statistical analysis showed significant differences between the expression of nuclear $\beta$-catenin SW480 and COLO320DM cell lines $(39.80 \pm 18.94$ vs. $66.72 \pm 22.69, p<0.05)$, and between cell line HCT116 and COLO320DM $(42.85 \pm 17.38$ vs. $66.72 \pm 22.69, p<0.05)$, whereas no significant differences $(39.80 \pm 18.94$ vs. $42.85 \pm$ 17.38) [Figure 1b] were noted from the comparison between the expression of nuclear $\beta$-catenin SW480 and HCT116 cell lines.

\section{Differences in the intensity of E-cadherin expression in SW480, COLO320DM, and HCT116 cell lines}

Observations on the intensity of E-cadherin expression were carried out by counting all cells in one field of view using ImageJ analysis software. Observations were made on eight fields of view, and the intensity of the E-cadherin expression was calculated using the MFI) unit [Figure 2a]. Further, the Kruskal Wallis test was used to notice the differences in $\mathrm{E}$-cadherin expression, and the mean of $\mathrm{E}$-cadherin expression was $40.30 \pm 5.77 \mathrm{MFI}$ in the SW480 cell line, $62.07 \pm 15.2 \mathrm{MFI}$ in COLO320DM cell line, and $61.75 \pm 14.69 \mathrm{MFI}$ in HCT116 cell line. The statistical analysis revealed significant differences in E-cadherin expression between SW480 cell line and COLO $320 \mathrm{DM}$ cell line $(40.30 \pm 5.77$ vs. $62.07 \pm 15.2$, p < $0.05)$, and between SW480 and HCT116 (40.30 \pm 5.77 vs. $61.75 \pm 14.69, p<0.05)$. However, E-cadherin expression in the COLO320DM cell line did not show any significant differences compared to the HCT116 cell line $(62.07 \pm 15.2$ vs. $61.75 \pm 14.69)$ [Figure $2 b$ ].

\section{Differences in $\mathrm{N}$-cadherin expression in SW480, COLO320DM, and HCT116 cell lines}

The intensity of $\mathrm{N}$-cadherin expression was done by counting all cells in one field of view using ImageJ analysis software. Observations were made on eight fields of view, and the $\mathrm{N}$-cadherin expression was calculated using the MFI unit [Figure 3a].

The Kruskal Wallis test was used to see the difference in $\mathrm{N}$-cadherin expression intensity, and the mean result of the $\mathrm{N}$-cadherin expression was $37.06 \pm$ 3.47 MFI in the SW480 cell line, $65.21 \pm 15.60 \mathrm{MFI}$ in COLO320DM cell line, and $67.06 \pm 7.94 \mathrm{MFI}$ in HCT116 cell line. Based on the statistical analysis, the results were almost the same as the expression of E-cadherin. These results indicated significant differences in $\mathrm{N}$-cadherin expression between SW480 cell line and COLO320DM cell line $(37.06 \pm 3.47$ vs $65.21 \pm 15.60$, p $<0.05)$ and between SW480 cell line and HCT116 cell line $(37.06 \pm 3.47$ vs. $67.06 \pm 7.94, p<0.05)$. Similar to E-cadherin expression, $\mathrm{N}$-cadherin expression did not show any significant differences between COLO320DM and HCT116 cell lines $(65.21 \pm 15.60$ vs. $67.06 \pm 7.94)$ [Figure 3b].

The observations on E-cadherin and $\mathrm{N}$-cadherin expressions showed nearly the same results that in SW480 (CRC Duke B stage) cell line model, E-cadherin expression was low and increasing along with the increasing CRC stages, namely, COLO320DM (Duke C) and HCT116 (Duke D). These results were also found in $\mathrm{N}$-cadherin expression; although COLO320DM (Duke C) and HCT116 (Duke D) 


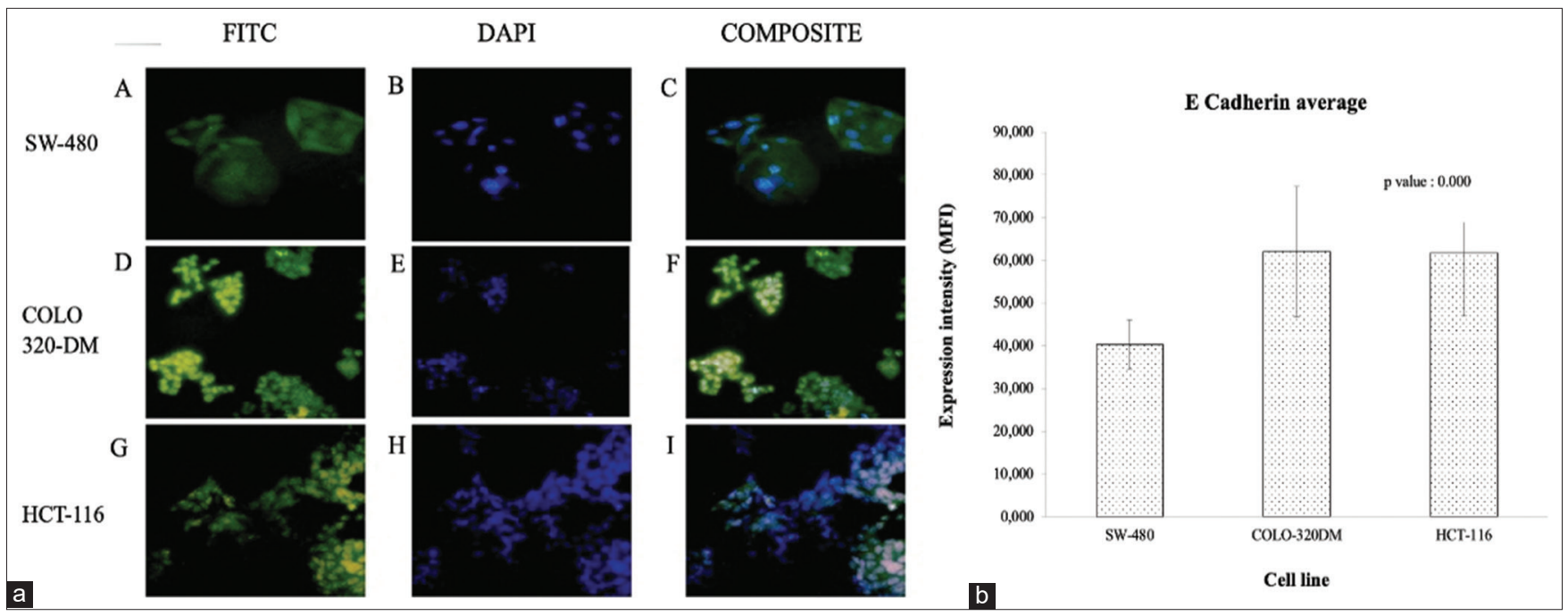

Figure 2: Differences in the intensity of E-cadherin expression in SW480, COLO320DM and HCT116 cellines. Observasion using immunofluorescence was done to evaluate the expression of E-cadherin (FITC), nucleus (DAPI) and composite to evaluate the expression of E-cadherin in cytoplasm and nucleus (a). The bar chart shows the mean of differences in the intensity of E-cadherin with significant results $(p<0.05)(b)$

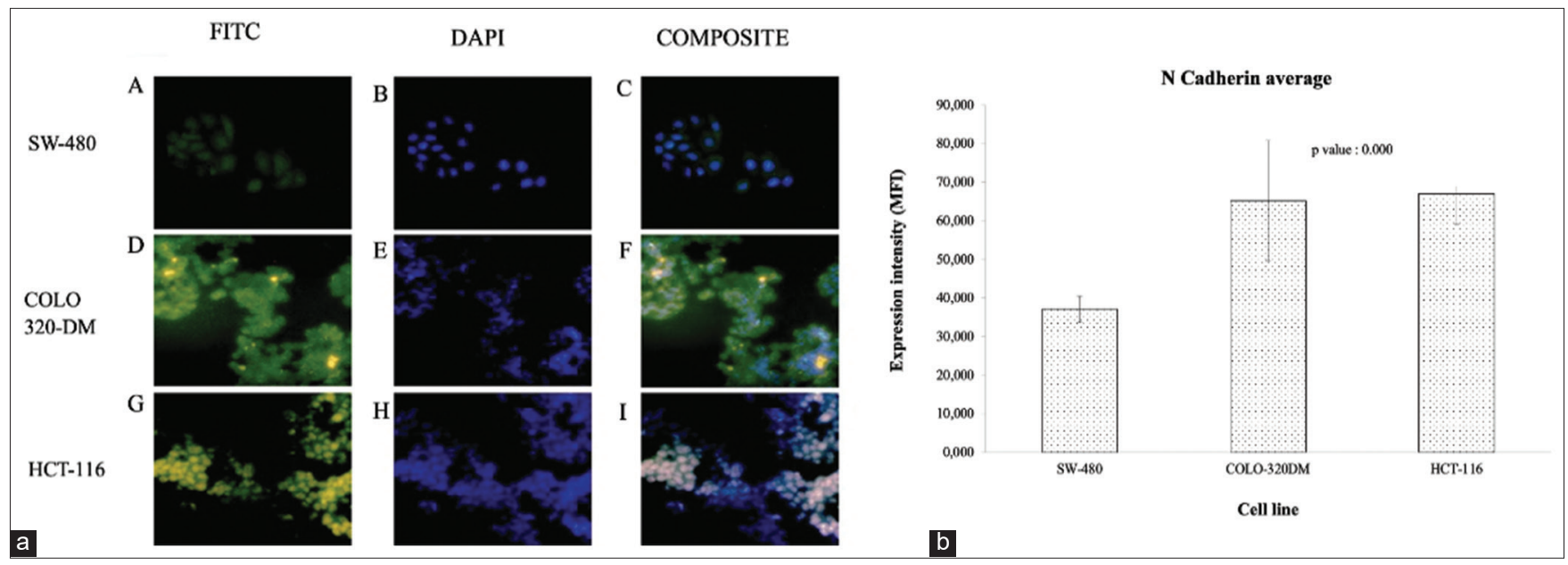

Figure 3: Differences in the intensity of $\mathrm{N}$-cadherin expression in SW480, COLO320DM and HCT116 cellines. Observasion using immunofluorescence was done to evaluate the expression of E-cadherin (FITC), nucleus (DAPI) and composite to evaluate the expression of $\mathrm{N}$-cadherin in cytoplasm and nucleus (a). The bar chart shows the mean of differences in the intensity of $\mathrm{N}$-cadherin with significant results $(p<0.05)(b)$

were not significant, the highest expression was found in the HCT116 cell line (Duke D).

\section{Differences in the expression of nuclear $\beta$-catenin, cytoplasmic $\beta$-catenin, E-cadherin, and $\mathrm{N}$-cadherin on SW480 cell line model (Duke B)}

This study also analyzed the expression intensity of nuclear $\beta$-catenin, cytoplasmic $\beta$-catenin, $\mathrm{E}$-cadherin, and $\mathrm{N}$-cadherin on the SW480 cell line model, which is the initial stage of CRC (Duke B). The differences in the intensity of the expression of cytoplasmic and nuclear $\beta$-catenin were analyzed using the Mann-Whitney test, while the difference in the intensity of the expression of E-cadherin and $\mathrm{N}$-cadherin was examined using the independent t-test. The analyses showed significant differences between the expressions of nuclear $\beta$-catenin and cytoplasmic $\beta$-catenin ( $39.80 \pm 18.94$ vs. $25.28 \pm 9.63$, $p<0.05)$ so that the expression of nuclear $\beta$-catenin was higher than that of cytoplasm $\beta$-catenin. However, the expression of $\mathrm{E}$-cadherin and $\mathrm{N}$-cadherin in the SW480 cell line model did not show significant differences $(38 \pm 9.63$ vs. $37.06 \pm 3.47, p>0.005)$ [Figure 4].

\section{Discussion}

The present study reports that the expressions of cytoplasmic and nuclear $\beta$-catenin, E-cadherin, and $\mathrm{N}$-cadherin are significantly different among the three 


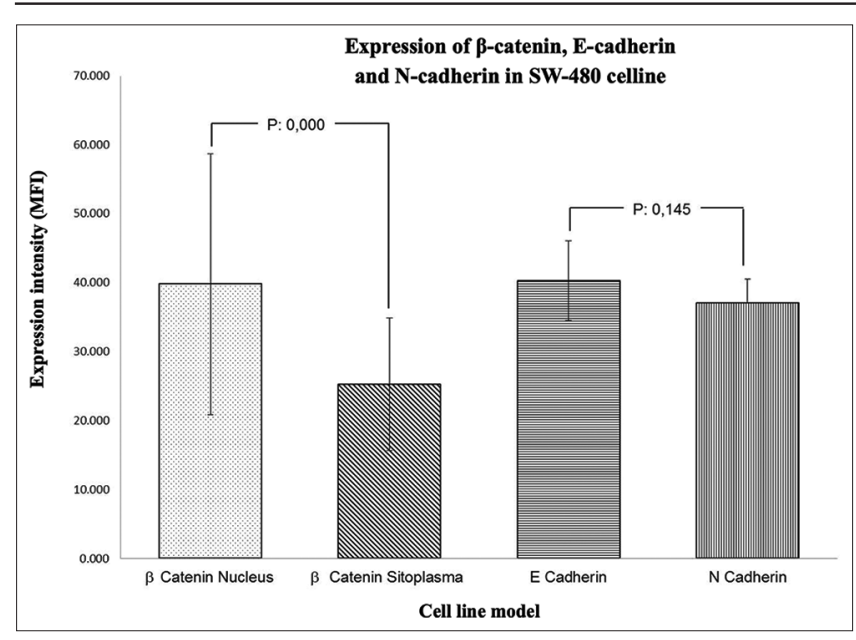

Figure 4: Differences in the expression of nuclear/cytoplasmic $\beta$-catenin, E-cadherin and $\mathrm{N}$-cadherin expression in SW480, COLO320DM and HCT116 cellines. The bar chart shows the comparison of the expression of nuclear and cytoplasmic $\beta$-catenin with significant result $(p<0.05)$. In contrast, there is no significant result of the expression between the intensity of E-cadherin and $N$-cadherin $(p>0.05)$

cell lines of CRC. Notably, there are high expression levels of nuclear $\beta$-catenin and $\mathrm{N}$-cadherin in the SW480 cell line (refers as Duke B CRC) although still at an early stage of CRC.

This study compares the expression of cytoplasmic and nuclear $\beta$-catenin in the three cell lines, SW480, COLO 320DM, and HCT116, which describe three CRC stages, i.e. Duke B (SW480), Duke C (COLO320DM), and Duke D (HCT116). The results show significant differences among the three. A study by Gao et al. that compared the expression of $\beta$-catenin in membranes, cytoplasm, and nucleus verified that differences in the expression levels of $\beta$-catenin in the membrane, cytoplasm, and nucleus were closely related to morphological patterns, EMT process, and poor prognosis of CRC [27].

This study also shows significant differences in the expression of E-cadherin among the three cell lines, SW480, COLO320 DM, and HCT116. This is in line with the research by Kim et al. that performed a meta-analysis of $\mathrm{CDH} 1$ (E-cadherin) levels on approximately 50,000 samples. It revealed differences in the expression of $\mathrm{CDH} 1$ (E-cadherin) in early-stage cancer cells compared to those that had already undergone infiltration [28]. However, the present study obtains new evidence different from the theory that the expression of E-cadherin should decrease along with the increase in the CRC stage; yet, in this study, the expression of E-cadherin increases. Loh et al. stated that the loss of E-cadherin, which is related to the occurrence of the EMT process, is an uncertain theory [15]. It is also acknowledged that some cancer cells (prostate, ovarian, and glioblastoma) experiencing metastasis are associated with high E-cadherin expression [17]. This phenomenon is called the dual role of E-cadherin, which will trigger metastases but inhibits the progression of tumor cells. This mechanism can be explained by the two forms of E-cadherin, namely membrane-tethered E-cadherin and soluble E-cadherin. Membrane-tethered E-cadherin is associated with strong intercellular bonds, and soluble E-cadherin is associated with increased migration and proliferation of cancer cells [15], [17].

This study indicates significant differences in the expression of $\mathrm{N}$-cadherin in the three cell lines, SW480, COLO320 DM, and HCT116, and there is a correlation where $\mathrm{N}$-cadherin expression is increasing along with higher CRC stage. In a study on 37 isolated CRC samples, Ye et al. found a correlation between $\mathrm{E}$-cadherin and $\mathrm{N}$-cadherin levels with the CRC stage. Their study concluded that E-cadherin expression was higher at Dukes' A/B stage compared to CRC Dukes' C/D stage; but, at Dukes' C/D stage, $\mathrm{N}$-cadherin expression was higher than at Dukes' $\mathrm{A} / \mathrm{B}$ stage [29]. As an initial stage of CRC (37.06 MFI) and just slightly different from the E-cadherin expression (40.30 MFI), a high $\mathrm{N}$-cadherin expression in SW480 cell line shows new evidence that adhesion and polarity between cells at the early stages of CRC have possibly been decreasing, and there is an accumulation of $\mathrm{N}$-cadherin protein which results in the EMT process [30].

Through this study, the researchers also examined the expression of the biomarkers of cytoplasmic and nuclear $\beta$-catenin, E-cadherin, and $\mathrm{N}$-cadherin on SW480 cell line that is the early stage of CRC (Duke B). This study obtains new evidence different from the general theory on SW-480 cells where the expression of nuclear $\beta$-catenin is higher than the cytoplasmic expression, even though the SW480 cell line is still in the early stage (Duke B) [31]. Theoretically, at the early stage, the Wnt signal is not yet active and causes $\beta$-catenin to accumulate in the cytoplasm and has not been translocated into the nucleus to activate the target gene, so the cytoplasmic $\beta$-catenin expression should be higher than the nucleus [13], [32]. However, Chen et al. concluded that a decrease in Wnt signal activity in SW480 cells was able to increase the invasion power of the cell or the entry of $\beta$-catenin into the nucleus [33]. This study shows contradictory results because until now the progression and invasiveness of cancer occur due to Wnt signal activity and will cause translocation of $\beta$-catenin into the nucleus [33]. The presence of $\beta$-catenin expression in the nucleus of SW480 cells proves that in the early stage of CRC (Duke B), $\beta$-catenin has invaded and migrated into the nucleus, which resulted in target gene transcription and led to the EMT process (Myc, Cyclin, Axin2) [11], [13]. The high expression of nuclear $\beta$-catenin in Duke $B$ stage of CRC indicates an active Wnt signal that will affect the possibility of drug efflux, cancer stem cells, apoptosis inhibition, and the EMT process, resulting in resistance to chemotherapy of CRC [11], [12]. 


\section{Conclusion}

This study concludes that in three CRC cell line models, SW480, COLO320DM, and HCT116, the differences in the expression of cytoplasmic and nuclear $\beta$-catenin, E-cadherin, and $\mathrm{N}$-cadherin biomarkers show differences in proliferation, migration, and metastasis capabilities of these cancer cells. A higher expression of nuclear $\beta$-catenin than the cytoplasm at the early stages of $\mathrm{CRC}$ and an increase in E-cadherin expression in line with the increase in the CRC stage revealed from this study will promote new theories related to the possibility of CRC progression at an early stage will unwrap the chances for chemotherapy resistance.

\section{Acknowledgment}

The authors thank the Postgraduate Program of Universitas Brawijaya for the support and the Parasitology Laboratory and the Biomedical Laboratory, Faculty of Medicine, Universitas Brawijaya, Malang for providing the laboratory facilities.

\section{References}

1. Zarkavelis G, Buossios S, Papadaki A, Katsanos $\mathrm{KH}$, Chistodoulou DK, Pentheroudakisa G. Current and future biomarkers in colorectal cancer. Ann Gastroenterol. 2017; 30(6):613-21.

PMid:29118555

2. Palaghia M, Mihai C, Lozneanu L, Ciobanu D, Trofin AM. E-cadherin expression in primary colorectal cancer and metastatic lymph nodes. Rom J Morphol Embryol. 2016;57(1):205-9.

PMid:27151709

3. Ahmad A, Stromberg VH. Expression of $\beta$-catenin and E-cadherin, their clinical significance and association with complexity and index of colon carcinoma. Adv Genet Eng. 2016;5(3):1-10. https://doi.org/10.4172/2169-0111.1000156

4. Akkoca AN, Yanik S, Ozdemir ZT, Cihan FG, Sayar S, Cincin G, et al. TNM and Modified Dukes staging along with the demographic characteristics of patients with colorectal carcinoma. Int J Clin Exp Med. 2014;7(9):2828-35.

PMid:25356145

5. Saltz LB. Colorectal Cancer: Evidence-based Chemotherapy Strategies. Totowa, New Jersey: Humana Press; 2007. p. 134-6.

6. Housman G, Byler S, Heerboth S, Lapinska K, Longacre M, Snyder N, et al. Drug resistance in cancer: An overview. Cancers. 2014;6:1769-92. https://doi.org/10.3390/cancers6031769 PMid:25198391

7. Colussi D, Brandi G, Bazzoli F, Ricciardiello L. Molecular pathways involved in colorectal cancer: Implications for disease behavior and prevention. Int J Mol Sci 2013;14(8):16365-85. https://doi.org/10.3390/ijms140816365

\section{PMid:23965959}

8. Xu Y, Pasche B. TGF- $\beta$ signaling alterations and susceptibility to colorectal cancer. Hum Mol Genet. 2007;16:14-20.

\section{PMid:17613544}

9. Chen J, Xie ZR, Wu Y. Computational modeling of the interplay between cadherin-mediated cell adhesion and wnt signaling pathway. PLoS One. 2014;9(6):1-12. https://doi.org/10.1371/ journal.pone. 0100702

10. Heuberger J, Birchmeier W. Interplay of cadherin-mediated cell adhesion and canonical wnt signaling. Cold Spring Harb Percpect Biol. 2010;2(2):a002915. https://doi.org/10.1101/ cshperspect.a002915

PMid:20182623

11. Zhong Z, Virshup DM. Wnt signaling and drug resistance in cancer. Mol Pharmachol. 2020;97(2):72-89. https://doi. org $/ 10.1124 / \mathrm{mol} .119 .117978$ PMid:31787618

12. Yuan $S$, Tao F, Zhang $X$, Zhang $Y$, Sun $X$. Role of Wnt $/ \beta$-catenin signaling in the chemoresistance modulation of colorectal cancer. BioMed Res Int. 2020;2020:9390878. https://doi. org/10.1155/2020/9390878

PMid:32258160

13. Shang $\mathrm{S}$, Hua $\mathrm{F}$, Hu ZW. The regulation of $\beta$-catenin activity and function in cancer: Therapeutic opportunities. Oncotarget. 2017;8(20):33972-89. https://doi.org/10.18632/ oncotarget. 15687 PMid:28430641

14. Menezes ME. The Wnt/ $\beta$-catenin signaling pathway in epithelial mesenchymal transition. Post Doc J. 2014;2(7):1-9.

15. Loh C, Chai JY, Tang TF, Wong WF, Sethi G, Shanmugam MK, et al. The E-cadherin and $\mathrm{N}$-cadherin switch in epithelial to mesenchymal transition: Signaling, therapeutic implications, and challenges. Cells. 2019;8(10):1-33. https://doi.org/10.3390/ cells8101118

PMid:31547193

16. Wheelock MJ, Shintani Y, Maeda M, Fukumoto Y, Johnson KR. Cadherin switching. J Cell Sci. 2007;121(6):727-35. https://doi. org/10.1242/jcs.000455

PMid:18322269

17. He X, Chen Z, Jia M, Zhao X. Downregulated E-cadherin expression indicates worse prognosis in Asian patients with colorectal cancer: Evidence from meta-analysis. PLoS One. 2013;8(7):1-8. https://doi.org/10.1371/journal.pone.0070858 PMid:23923027

18. Kourtidis A, Lu R, Pence L, Anastasiadis PZ. A central role for cadherin signaling in cancer. Exp Cell Res. 2018;358(1):78-85. https://doi.org/10.1016/j.yexcr.2017.04.006

PMid:28412244

19. Barbierato I, Argentini C, Skaper SD. Indirect immunofluorescence staining of cultured neural cells. Methods Mol Biol. 2012;846:235-46. https://doi.org/10.1007/978-1-61779-536-7_21 PMid:22367816

20. Scheffler JM, Schiefermeier N, Huber LA. Mild fixation and permeabilization protocol for preserving structures of endosomes, focal adhesions and actin filaments during immunofluorescence analysis. Methods Enzymol. 2014;535:93102. https://doi.org/10.1016/b978-0-12-397925-4.00006-7 PMid:24377919

21. Novus Biologicals. Immunocytochemistry (ICC) Handbook; 2017. Available from: http://www.bio-techne.com. [Last accessed on 2021 May 10].

22. Jalali M, Saldanha FY. Basic science methods for clinical researchers. In: Basic Science Methods for Clinical Researchers. United States: Academic Press; 2017. https://doi.org/10.1016/ 
b978-0-12-803077-6.00027-8

23. Stadler C, Rexhapaj E, Singan VR, Murphy RF, Pepperkok R, Uhlén $\mathrm{M}$, et al. Immunoflourescence and fluorescent-protein tagging show high correlati on for protein localization in mammalian cells. Nat Methods. 2013;10(4):315-23. https://doi. org/10.1038/nmeth.2377

24. Alhabbab RY. Immunofluorescence (IF) assay. In: Basic Serological Testing. Berlin, Germany: Springer; 2018. p. 119-26.

25. Cox G. Fundamentals of Fluorescence Imaging (G.Cox,ed) 2019. Available from: http://www.link.spinger.com/10.1007/9783-0348-8376-4. [Last accessed on 2021 May 10].

26. Hoff H. How to Prepare Your Specimen for Immunofluorescence Microscopy; 2015. Available from: https://www.leica-microsystems. com/science-lab/how-to-prepare-your-specimen-forimmunofluorescence-microscopy. [Last accessed on 2021 May 10].

27. Gao Z, Lu C, Wang M, Han Y, Guo L. Differential $\beta$-catenin expression levels are associated with morphological features and prognosis of colorectal cancer. Oncol Lett. 2014;8(5):2069-76. https://doi.org/10.3892/ol.2014.2433

PMid:25295092

28. Kim WK, Kwon $\mathrm{Y}$, Jang $\mathrm{M}$, Park M, Kim J, et al. $\beta$-catenin Activation Down-regulates Cell-cell Junction-related Genes and Induces Epithelial-to-mesenchymal Transition in Colorectal Cancers. https://doi.org/10.1038/s41598-019-54890-9
29. Ye Z, Zhou M, Tian B, Wu B, Li Z. Expression of IncRNACCAT1, E-cadherin and N-cadherin in colorectal cancer and its significance. Int J Clin Exp Med. 2015;8(3):3707-15.

PMid:26064266

30. Liang X, Xu X, Wang F, Chen X, Li N, Wang C, et al. E-cadherin knockdown increases $\beta$-catenin reducing colorectal cancer chemosensitivity only in three-dimensional cultures. Int J Oncol. 2015;47(4):1517-27. https://doi.org/10.3892/ijo.2015.3137 PMid:26316041

31. Ueno $H U$, Price $A B$, Wilkinson $K H$, Jass JR, Mochizuki $H$, Talbot IC. A new prognostic staging system for rectal cancer. Ann Surg. 2004;240(5):832-39. https://doi.org/10.1097/01. sla.0000143243.81014.f2

PMid:15492565

32. Yoshida N, Kinugasa T, Ohshima K, Yuge K, Ohchi T, Fujino S, et al. Analysis of Wnt and $\beta$-catenin expression in advanced colorectal cancer. Anticancer Res. 2015;35(8):4403-10.

PMid:26168479

33. Chen GT, Tifrea DF, Murad R, Lyou Y, Mortazavi A, Edwards RA et al. Disrupting $\beta$-catenin Dependent Wnt Signaling Activates an Invasive Gene Program Predictive of Colon Cancer Progression. Berlin, Germany: ResearchGate; 2019. https://doi. org/10.1101/667030 